NOTE: This is an article that was published through OnlineFirst in the Journal of Material Culture on 09/01/2020. This copy is the version accepted by the journal after two rounds of review, but prior to typesetting. In the version below, some proofreading errors may remain, and a few very minor differences between this version and the final published version may exist (difference in phrasing, etc), but the contents, argument and style remain the same.

\title{
The smell of Shōwa: time, materiality and regimes of value in Japan's second-hand kimono industry
}

This article maps the way second-hand kimono pass between different regimes of value as they move out of people's homes and into second-hand shops. Joining recent calls for a greater anthropological focus on the processes of divestment and disposal, I highlight how kimono move from the inalienable space of the domestic sphere and into the alienable domain of retail, and I consider how their materiality - worn fabrics, dated aesthetics and musty smell - is an active agent in the transformation of value. When initially purchased, the symbolic and economic value of kimono is congruent. But with the passage of time and the deterioration of materials and fraying of kinship bonds, their value as treasured family possession is diminished. Yet the very materiality that caused their loss of economic and symbolic value, their undesirable smells, colours, designs can cause them to enter a new regime of value as vintage fashion supported by fashion magazines. By rethinking Arjun Appadurai's regimes of value with greater focus on material properties and qualities, this article aims to link cycles of divestment and consumption practices with the generation, loss and re-creation of value.

Keywords: second-hand, kimono, divestment, materiality, time, regimes of value

This article is based on twelve months of doctoral fieldwork between 2015 and 2016 in Toyota (central Japan), during which I worked in a second-hand shop and conducted extensive interviews both in the kimono industry and among people concerned with what to do about their kimono collections.

By the end of my fieldwork, I had amassed an impressive array of second-hand kimono. None of these I purchased myself. Women throughout my neighbourhood in Toyota and in my extended network of contacts, seemed to have an unending array of kimono that were no longer wanted. These were pressed into my hands and I returned to Europe with an excess of $40 \mathrm{~kg}$ of kimono. For the most part, these kimono were what could be called vintage pieces - dating from the early 1950s, 60s and 70s, but some were pre-war pieces. There were silk formal kimono, fit for weddings, and informal woolen kimono, which, at the time they were made in the immediate post-war period, would have been worn at New Year's. A great many of these kimono came from women's bridal trousseaux - a collection of kimono put together by parents before their daughter's wedding so that she would have kimono to wear throughout her life (Valk 2018, Valk forthcoming). 
I would bring these kimono to a trusted friend and research participant, Keiko Takeda, for her opinion. As I took the kimono out from their tatōshi (Japanese paper wrappings), a smell of cupboards, dust and mothballs wafted out. Keiko looked up at me knowingly and said, 'ah, the smell of Shōwa'. Shōwa is an era of modern Japanese history, dating from 1926 to 1989, and for Keiko these kimono, and the very era itself, had a particular smell.

The kimono is not a high-profile topic of study in anthropology. Existing studies are primarily historical in nature (Milhaupt 2014) or explore the kimono as a signifier of gendered national identity (Dalby 2001, Goldstein-Gidoni 1999). This article seeks to explore the kimono from a completely different angle, by tracing what happens to the kimono that 'smell of Shōwa' when they are sold to second-hand kimono shops and move through different regimes of value.

\section{Situating second-hand clothing in anthropological understandings of value}

As Fred Myers points out, 'value' in anthropology has been explored in a relatively undertheorised way (Myers 2001: 55). David Graeber put forward the need for a theory of value that defined the word in the broadest terms: that which 'is beautiful, or worthwhile, or important' (Graeber 2001: ix). Arjun Appadurai focused on the production of value in economic terms, and examined value specifically in the context of commodities. In the case of commodities, it is the act of exchange itself that generates value (Appadurai in Pearce 1994: 76). Igor Kopytoff famously added 'use value' to this definition of commodity, and tracked the various ways that value is generated in a commodity through its potential exchange, 'singularisation' through removal from the market, and then through commodification once more as it re-enters exchange, acquiring a 'biography' in the process (Kopytoff in Appadurai 1986). In her equally famous exploration of Maussian theory with regards to 'inalienable wealth', Annette Weiner argued that it is through inalienable association with people that object gain high levels of value (Weiner 1992), and thus it is by withholding the object from exchange that value is produced (Thomas 1991: 31).

What emerges from these different anthropological explorations of value is that anthropologists have identified the existence of different types of value, systems which are sometimes congruent, sometimes opposed to each other. With regards to this categorization of value, Appadurai put forward the concept of 'regimes of value' (Appadurai 1986: 4). This concept remains under-used, in part due to the difficulty in pinning down value itself. As Myers writes, regimes of value are 'multiple, coexisting, and variously related' and value itself is 'subject to slippage', rarely fixed and continually evolving (Myers 2001: 6). I argue that it is the materiality and movement of things in and out of different contexts that enable us to perceive and highlight regimes of value. Movement between regimes of value is what enables value itself to be constituted, reformulated or, alternatively, devalued. Susan Pearce has noted that 'objects can be subject to great fluctuations in value' as they move into different spaces, such as from a dusty attic to a museum collection (Pearce 1994: 2).

In this article, I will show how Japanese kimono move in and out of regimes of value when they are sold to second-hand shops, moving from a regime of value which is symbolic and 
singularised, to an economic regime in which they are commodities. In opposition to Igor Kopytoff, who argues that 'commoditization homogenizes value' (Kopytoff in Appadurai 1989: 73), I argue that symbolic regimes of value are sticky - even when reinserted back into the world of commodities, second-hand kimono retain the ghost of their former owners. This sticky symbolic value, particularly the relationship of kimono to bodies, has to be negotiated, usually causing the economic value of the kimono to plummet. Finally, I demonstrate how a lucky few of these kimono can acquire new symbolic value and desirability through the current fashion trends for vintage kimono, demonstrating how malleable and variable value can be. Finally, discussions of value have overwhelmingly focused on acquisition, consumption, collection and circulation as the key means through which value is generated, but a growing area of literature has begun to focus the way value is created through processes of divestment, displacement, destruction and loss (see Weiss 1997, Hetherington 2005, Daniels 2009 and Bille et al 2010). Inge Daniels has questioned the corollary of Annette Weiner's theory of inalienable wealth which is that the material integrity or objects has to be maintained and protected from loss of destruction: 'loss and the using up of objects may play an important role in social processes of regeneration' (Daniels 2009: 386).

Through an analysis of second-hand kimono, a topic that has not received extensive academic attention so far (Milhaupt in Palmer and Clark 2005: 82), this article will add a Japanese case study to anthropological theories of value, but also to a growing body of literature on disposal and divestment as well as to debates on second-hand businesses and vintage fashion.

\section{Value, authenticity and cultural capital: the kimono in the second half of the $20^{\text {th }}$ century}

The kimono in contemporary Japan is worn quite seldom, and most usually for ceremonial occasions (Dalby 2001, Milhaupt 2014, author 2018). The kimono is wrapped around the body and secured in place first with various items including koshihimo (thin belts) and then a decorative obi sash. Kimono are tailored from a single bolt of cloth referred to as a tanmono, which is between 12 and $13 \mathrm{~m}$ long and between 37 and $40 \mathrm{~cm}$ wide. Kimono are almost always sold as bolts of cloth, which customers select in specialist shops. The cloth is tailored to the customer's specific measurements and sewn up accordingly. Kimono vary in price, and depending on the fabric (mostly silk, linen, cotton or polyester) they can range anywhere between $£ 400$ and $£ 20,500$. An average price for a new kimono typically hovers ranges between $£ 1,400$ and $£ 3,500$. This high price is due to a number of factors: the materials (often silk for formal kimono and some informal kimono), the fact that they are made to order and the fact that 'extras' (obi sashes, undergarments, etc.) are often added to the overall order, increasing the price significantly. The kimono retail industry has also been particularly adept at building the reputation of certain regional textile crafts as truly 'authentic', and mark up the price accordingly. Further, the type of craftsperson, their skill level and the recognition given by the government to their craft are also features which drive up the price of the kimono. For example, kimono that have been made by a craftsperson classified as a 'Holder of Important Intangible Cultural Property' (more commonly referred to as ningen kokuhō or 'living national treasure') by the Agency for Cultural Affairs for the quality and 'authentically traditional' nature of their work were often so expensive as to be out of reach of all the wealthiest of customers. Kimono that have been made by a Ministry of Economy, Trade and Industrycertified dentō kōgeishi ('master of traditional craft') are not quite as prohibitively expensive but 
still very much highly prized. Beyond a purely aesthetic aspect, these certifications by the government add significantly to the cultural capital of a kimono.

Kimono are also classified as either formal wear to be worn at weddings, funerals, and other ritual occasions, and informal, which is further split into different levels of informality. They are tailored to one specific person, but the stitching process is very versatile, meaning that the kimono can be re-stitched or even re-dyed to fit a different person. This feature is also used to justify the kimono's high price: when purchasing a kimono, my middle-aged participants tell me, they are thinking not just of themselves, but hope that their daughters and grand-daughters will wear it one day. During my fieldwork I heard many skilled shop owners make a sales pitch based on the idea that the kimono they were trying to sell would one day make a great kimono for the customer's daughter - regardless of the fact that these trans-generational transmission often do not happen smoothly (see author forthcoming). In $21^{\text {st }}$ century Japan, few people actually know how to wear a kimono: it must be wrapped around the body and secured with sashes and belts, and those wishing to wear a kimono often need to learn exactly how to do this. From the outset, kimono have a very particular relationship with the human body, since they are tailored specifically for one person, contributing to their feel of 'singularity', but also feel very different when worn for the vast majority of Japanese people who are used to the feel of Western clothes.

After World War Two, the kimono underwent a process of formalisation whereby it was increasingly removed from day to day wear and became used primarily for ritual occasions such as weddings, coming of age ceremonies, funerals, graduations and school entrance ceremonies (Dalby 2001: 126). All of my research participants who worked in shops and in wholesale confirmed that, following this process of formalisation and close association with ritual occasions rather than everyday wear, the price of the kimono increased. The pricing of a brand new kimono, typically tailored for a single person, varies extensively as pricing is left to the discretion of each individual shop or chain, but the typical range is between $£ 200$ for a very simple cotton kimono and several thousands of pounds for a formal silk kimono. Other items, such as a cotton yukata or summer kimono, often mass-produced, can be purchased much more cheaply. These kimono's high price tags are associated with two sources of value. Firstly, their price is associated with their role in ritual, ceremonial occasions such as weddings and tea ceremonies. With Japan's postwar economic boom and the rise of a wealthy middle class, Japanese society developed a number of ways of demonstrating good upbringing, taste and manners befitting the middle-class. Among these, the kimono was marketed as an item required by a woman in the post-war period aspiring to demonstrate her family's newfound wealth and status. They were marketed, especially to well to do housewives, as the ultimate form of cultural capital. Pierre Bourdieu has famously argued that cultural capital, or the ways in which social groups can wield power and influence through their knowledge and understanding of particular cultural forms, aesthetics and tastes, can be found in three forms: institutionalised, embodied or objectified (Bourdieu in Richardson 1986: 243). As a result, these kimono were valuable items to demonstrate a woman's cultural capital and that of her family. As Dalby writes, 'without exaggerating, we can say that kimono are coded for messages regarding age, gender, season, formality, and occasion - not to mention wealth and taste' (Dalby 2001: 7). Understanding all these messages and being able to broadcast them well was considered key to a woman's cultural capital. Thus, a woman had to be able to correlated coordinated her outfit based on her age, the level of formality of the occasion, but also the right season. As Inge 
Daniels has noted, seasonal rituals in the domestic sphere have deep significance in Japanese day to day life (Daniels 2009: 174). Being able to demonstrate mastery of these codes demonstrates good taste and elevated cultural understanding; Kimono types, patterns and seasonality are deeply intertwined: a single-layered kimono in the summer, or wearing a kimono patterned with the right flower for the right season, such as irises for later April and May, or an obi with cherry blossom in February, March and April. The second dimension here is the association between price and the specific technique employed in making a kimono. Kimono types are typically divided into formal styles and informal styles. These styles often reflect regional techniques of weaving and dyeing. There is not enough space to list them all here, but a kimono type that was particularly prized among my research participants is the Ōshima tsumugi (pongee). Tsumugi is made using a mud dye and the pattern of the cloth is woven directly into the fabric itself rather than painted or dyed after weaving.

According to my research participants, and a view I heard repeatedly in Japan, was that Ōshima gained a reputation as stylish and refined, and was particularly sought after in the 1970s and 1980s due to the refined techniques and the painstaking, months-long process of fabrication that situates this textile in a tradition of authentic regional craftsmanship. It was also sought after because, even though the technique itself is very refined, such a kimono is classified as relatively informal, and could not be worn to a wedding or a tea ceremony for instance ${ }^{1}$. There are other kimono types, especially other forms of tsumugi material such as Yūki tsumugi, that occupy this niche - expensive but technically informal, with limited 'appropriate' occasions for wear, but among my research participants Ōshima was particularly prized. The knowledge regarding the authenticity of textile techniques and the ability to distinguish between types and wear them at appropriate events, played a key role in a woman's social and cultural capital in the second half of the $20^{\text {th }}$ century, particularly up until the late 1980 s. In parallel, the materials

\footnotetext{
${ }^{1}$ Particularly since, as a woven kimono, the cloth rustles and makes a noise, which would be considered distracting and poor manners during tea ceremonies.
} 


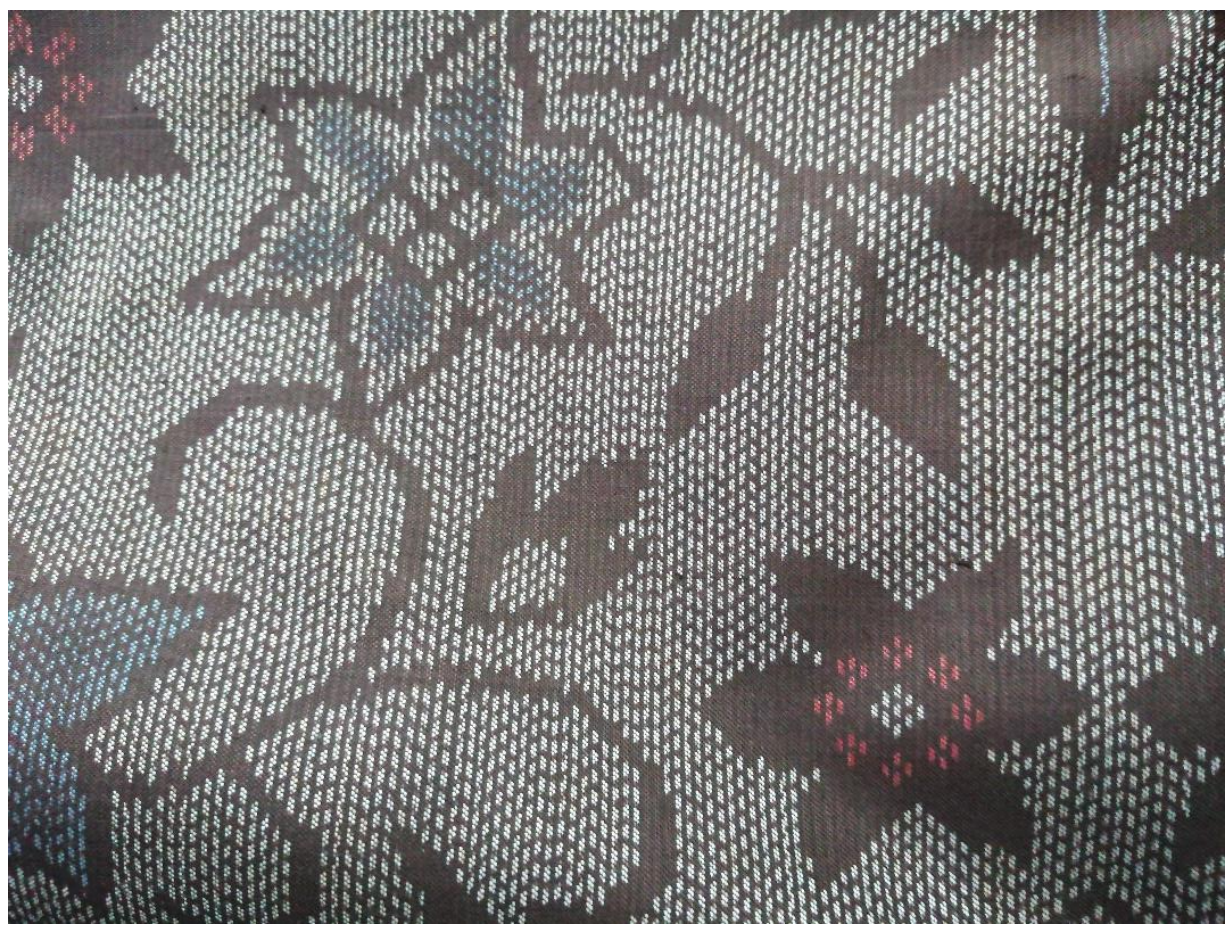

Figure 1. Ōshima tsumugi pattern (author's collection)

and techniques created a hierarchy of value, with particularly refined kimono types such as tsumugi types ranking near the top. Value itself was located within the fabrics, dyes and weaving styles. This social and cultural value was of course underscored by economic value as well: Ōshima tsumugi bolts of cloth are notoriously expensive.

However, the paradox of Japan's kimono in second half of the $20^{\text {th }}$ century is although it was considered to be of so much value that it was worth buying in large quantities for daughters getting married, it was not very often worn, and large kimono collections amassed in women's homes. What occurred next was a paradigm shift: this body of knowledge about the kimono started to become more alien, and less relevant to day to day life for younger women (Dalby 2001: 1). During my fieldwork in Toyota (central Japan) in 2015-2016, I interviewed 21 women aged between 41 and 82 years in their homes and asked them to show me their collections of kimono. One of the primary sources of these kimono is a woman's bridal trousseau (Valk 2018). This custom was very popular in the second half of the twentieth century when Japan's economy was booming, and bridal trousseau became increasingly lavish and expensive. By the 1960s, even families with modest incomes would provide at least 15 or more kimono. An upper class woman, originally from Kyoto, had come to marry her husband in Nagoya accompanied by a trousseau of over 200 kimono in her home. It should be noted that the size of a trousseau very much reflects the level of wealth in a family. Toyota, as the name would suggest, is the home of Toyota motors, and many middle aged people I had met there had been associated with the company at the peak of the economic boom and were thus wealthy and middle-class, and their parents would have been 
particularly invested in providing an extensive bridal trousseau for their daughters. There are also regional variations in terms of amounts and styles, with the wider region of Aichi in which Toyota is situated being renowned for lavish weddings and large bridal trousseau. That being said, the custom of the trousseau was very extensive, and lower income families in the 1960s to 1980s would also put together a trousseau for their daughters.

Up until the late 1980s, it was common for women to move into their husband's household upon marriage. According the Japanese kinship system, or ie, daughters are for the most part expected to marry out of their household of origin, and integrate the household of their husbands upon marriage (Imamura in Sugimoto 2009: 78-9), although in some cases, if a male heir is needed, a son-in-law will be officially adopted and he will take the family name. While the kinship system in Japan has evolved considerably and fewer young couples live with the husband's family than in the $20^{\text {th }}$ century, until the $1980 \mathrm{~s}$, there was a well-established custom of putting together a bridal trousseau for daughters getting married. The purpose behind this custom aimed at anchoring a new bride's social status in her new home and was designed to give daughters a life-long wardrobe of kimono to choose from (see author, forthcoming). These collections were very expensive to put together, the average trousseau costing around 10 million yen (roughly £68,721). They were also loaded with what Japanese parents refer to as oyagokoro, meaning the love and duty of parents to their children (see Valk, forthcoming).

In this sense, the kimono that made up the trousseau have multiple sources of value: their value is located in the techniques that went into making them and the cultural capital that parents wish for their daughters to have, but also in the intensely personal and familial value. The effort of choosing kimono for daughters, the financial expense and the emotional process of imagining the kimono that an adult daughter well into her 30s, 40s, 50s and beyond combine to create an especially powerful regime of value.

Kimono, however, are now only rarely worn and spend more time in their tansu than they do on people's bodies. This is especially the case for formal kimono that are only worn on a handful of occasions, and often require particularly good kimono dressing skills, which many women do not possess or do not feel confident about. Additionally, care and expensive upkeep can be required once they have been worn in order to clean dirt and sweat, and women are often reluctant to wear kimono, especially formal kimono, because of the effort involved, both in terms of wearing the kimono and caring for it afterwards. As a result of kimono building up in the home, the middleaged women in my research are frequently in the position of being 'kimono caretakers' for several generations of women in their family: they care for their own kimono, but also those of their grandmother, mother and daughters and sometimes other family members such as mother-in-laws. As a result, kimono that are never or only rarely worn build up in their homes. Many of the women I interviewed had devoted substantial energy to accommodating collections of kimono in their homes, often stored in large pieces of furniture known as tansu, and while they rarely wore their kimono they attempted, but were not often successful, in 'caring' for these kimono. The 'use value' of these kimono has declined since they are not worn, and women are increasingly faced with the question of what to do with the 'excess' of kimono in their home. They can choose from a variety of options. The first, and by far viewed as the most preferable, is to pass the kimono on to a new owner, ideally a daughter or close relative. However, daughters are often reluctant to accept the duty of caring for these collection. This can be because they do not wish to be burdened with the 
responsibility of caring for these clothes with a particularly strong emotional charge (see Valk forthcoming), but partly also for practical reasons: many young women, whether single or in a couple with children of their own, live in small apartments with little storage space, and kimono typically take up a lot of storage space. Failing that, a friend or acquaintance is also acceptable. This concern with the proper care of possessions when they are disposed of can be found across cultures (see Marcoux 2001) but in Japan there is an added dimension to this concern with care. As Inge Daniels describes in her work on gift-giving in Japan, her research participants 'stressed the importance of 'taking care of' their possessions, using the phrase taisetsu ni suru', whilst expressing a genuine concern about those things that are barred from forming a useful relationship with people' (Daniels 2009: 396). Daniels further states that 'in Japan the propensity for not throwing things away is more affected by a feeling of duty than emotional attachment. The duty people felt towards objects is grounded in an awareness of the interrelatedness of human and nonhuman entities. In other words, things offer their service to people who, in return, should be thankful and treat objects respectfully' (ibid). Beyond the cosmology of 'taking care' of material objects, there is often a keen association between kimono and female family members: those who wore them before, and also those who purchased them on behalf of my participants. This makes them particularly tricky to dispose of, as it produces feelings of guilt.

${ }^{2}$ Literally, to 'treat something as important', meaning to 'treat with care'. 


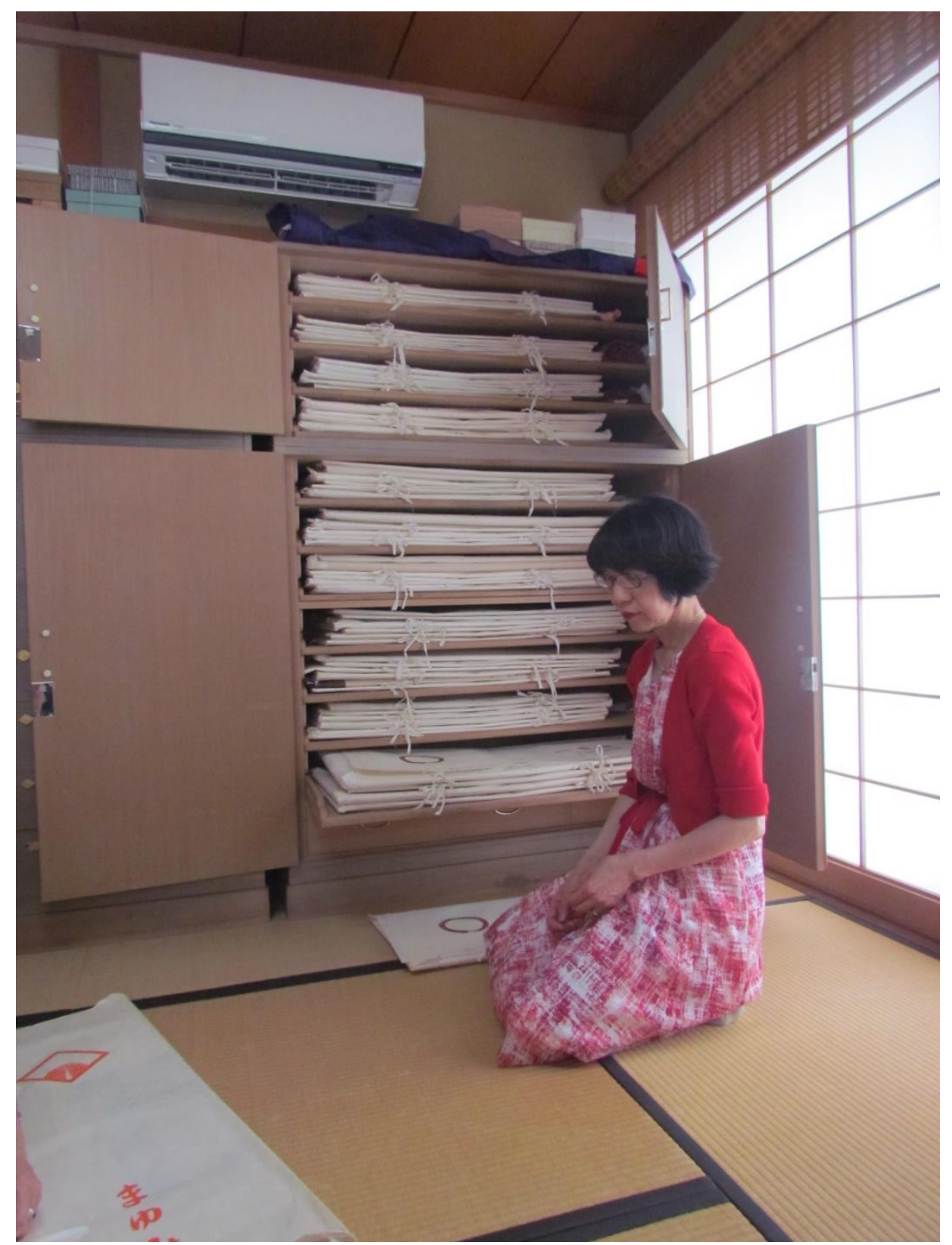

Figure 2. A research participant with her tansu full of kimono. These kimono are wrapped in protective paper wrappings known as tatōshi. She came from Kyoto to Nagoya to marry her husband with a large collection of kimono and obi.

There is another option open to women, which has become increasingly common since the 1990s, and that is to sell their kimono to second-hand shops. Daughters and relatives are unlikely to take on the entire collection, and so 'kimono caretakers' choose to sell their kimono to second hand shops. There is often strong resistance to doing this, however, because to do so in a sense 'betrays' the object by removing it from its symbolic regime of value within the home and 'commodifying' it by placing it in a second-hand shop, thereby making the transmission to a 'correct' family member or friend impossible. This resistance to disposal through second-hand 
shops was noted by one of my participants, Kano-san. She remarked, 'we all really wonder what we are going to do with all our kimono that we don't wear. There are second-hand shops, but, well... my kimono are good quality, and I have a lot of feelings attached to them.'

Lucy Norris has noted that there is a similar aversion to letting go of clothing through second-hand shops in India. As with Japanese women, by far the preferable option is for a family member to take on the clothes, and the least preferred option is to sell the clothes, an 'exchange of singular symbolic value for hard cash' (Norris 2004: 69). The abrupt transition from a singular status in a domestic regime of value to a complete economic sphere of value is an uncomfortable one, seen as it involves the commodification of an item with powerful associations. As a result, Japanese women are very selective when it comes to choosing what to sell. Materiality often influences the selection of clothing that is sold to second-and shops. Kimono that 'smell of Shōwa', i.e. that are dated and less valued, are often the first to be sold. From November 2015 to March 2016, I worked in a second-hand kimono shops called Go-Ichi-Maru in the city centre of Toyota in central Japan. The okami-san (senior female worker in a kimono shop), Goto-sensei, told me that when they opened their second-hand business in 2008 they initially received few items:

We got a lot of old things: a lot of red and purple which were popular in the Meiji (18681912) and Taishō eras (1912-1926). You can tell when a kimono was made from its colour. Red and purple are Meiji or Taisho era. It was after the classes had been abolished ${ }^{3}$, and people aspired to wear the colours of the upper classes. We also got lots of wool kimonos from after the war, and lots of short haori overcoats. We knew that would never sell.

After that initial phase, Goto-sensei noted that kimono flooded into their shop, sometimes at a rate of 2000 items per month. She told me that there are many people who come to sell:

Lots of couples brings us kimono when they have to move house. They don't know what's good or bad, and they say that the kimono are too jimi (dull) and that they don't like them. They say it doesn't fit them, even though it could be retailored to fit them.

It is often the case however that, given how expensive re-tailoring can be, women do not want to spend that kind of money on a second-hand kimono. Dating 1990s and especially in the 2000s, there has been an increase in kimono sold to second-hand kimono shops, so much so that the industry has grown significantly. In the next part of this article I will explore the way kimono enter new regimes of value as they enter the second-hand retail industry.

\section{Into a new regime of value: making fashion out of other people's kimono}

To date, the literature on second-hand clothing has been concerned primarily with two main issues: the first concerns globalization and the export of second-hand clothing from Western industrialised nations towards developing and emerging countries (see Haggblade 1990, Brookes 2013 and 2015, Norris 2015, Hansen 2000 and 2004a). Key figures include Karen T. Hansen and

\footnotetext{
${ }^{3}$ The social classes of samurai, artisans, farmers and merchants were abolished in 1871.
} 
her work on second-hand clothing in Zambia, where western donated clothes are immensely popular and indigenized to suit local fashions and identities (Hansen 2000) and Lucy Norris, who has examined the trade of second-hand clothing from Western nations to India (Norris 2015). The second area of focus has been charity shops, mainly in Western countries (Gregson, Brooks and Crewe in Jackson et al 2000 and Horne and Maddrell 2002). In this case, analyses of second-hand clothing tend to coincide with fashion, particularly in terms of the consumption of second-hand clothing as vintage and lifestyle (DeLong et al 2005); in this case, the fact that the clothes have been used before is itself a source of value in the eyes of the consumer (Gregson and Crewe 2003: 8). Another area of literature in which second-hand clothes features is through the practice of throwing out clothes and divestment practices (Marcoux 2001). Divestment practices are often examined in their own right, separate from the destinations of clothing in rubbish tips or secondhand shops. An exception is Lucy Norris' work tracing donated second-hand clothes from Western countries to Indian markets (Norris 2015). With a few exceptions, discussions of second-hand clothing in Japan remain unusual (Milhaupt in Palmer and Clark 2005: 82).

Second-hand clothing industries exist worldwide, predicated on excess production of clothing and a market for reusing worn clothes (Palmer and Clark 2005: 3). The second-hand clothing industry has existed in Japan since before the Edo period (1600-1868) and has always been a significant part of the retail landscape in Japan (Asaoka 2003, Cliffe 2017: 111). However, consumer preference for all things new and up-to-date was the norm during Japan's postwar economic growth, and second-hand shops of all kinds fell out of favour (Clammer in Shields 1992). Philomena Keet notes that by the 1990s, second-hand shops had begun to make a comeback through vintage fashion (Keet 2011). Second-hand kimono shops began to spread in the late 1990s and early 2000s, anywhere between small independent shops such as Go-Ichi-Maru to mega-chains such as Tansu-ya. Created in 1999 by Kenichi Nakamura, the heir to a long line of kimono shop owners, Tansu-ya is now the largest chain of second hand shops, comprising 120 shops $^{4}$ (Nakamura 2006: 5). Yasuko Suzuki notes that second-hand vintage kimono became increasingly popular during this period, fueling the growth of the industry (Editors of Nanaoh 2011: 11), and I will explore the reasons behind this later in this section. The growing popularity of second-hand kimono did not completely eliminated negative perceptions of second-hand kimono shops, however. Whilst I was working at Go-Ichi-Maru, Goto-sensei told me that 'you have to keep things nice and tidy. People are prejudiced about second-hand shops, and we have to show that things are done properly here, too. Like that they walk away thinking that second-hand kimono shops aren't so bad.'

This ambivalence towards second-hand clothing is not unique to Japan. The unknown origins of second-hand clothing carry 'notions of risk and fear' because of their association with 'unknown bodies' as opposed to the bodies of known relatives or friends (Gregson, Brooks and Crewe in Jackson et al 2000: 109). It is once more the relation to the body which means that customers harbor ambivalence towards second-hand clothes. This relation is inevitable, because, as Nicky Gregson and Louise Crewe note, the bodies of previous owners 'have literally left their marks, through personalized ways of wearing, smell and so on' (Gregson and Crewe 2003: 7). As a result, these items are potentially polluted and require 'rituals of divestment - cleansing,

${ }^{4}$ http://tansuya.jp/shop/ (retrieved 09/07/2018). 
purification and personalization - to enable them to enter new cycles of consumption' (ibid). This sense of risk associated with unknown bodies is even stronger if the person to whom the clothes belonged have passed away. Gregson, Brooks and Crewe found this taboo associated with death to be strongly at work in charity shops in the UK (Gregson, Brooks and Crewe in Jackson et al 2000: 116-7). These rituals are negotiated at the moment of transition. Many people who sell kimono to shops are conflicted in doing so, and may have many reasons for doing so, but they have reached the point where the physical absence of the kimono in the household has greater value than its presence. Part of the ritual of divestment is selection based on the value of the kimono: this happens first in the household, with people selecting kimono that are old and less likely to be used. Sometimes there is only minimal selection, as in the case of the couple who gave a large collection of kimono to Go-Ichi-Maru, handing over kimono to acquire the greater value of freed up space in the home.

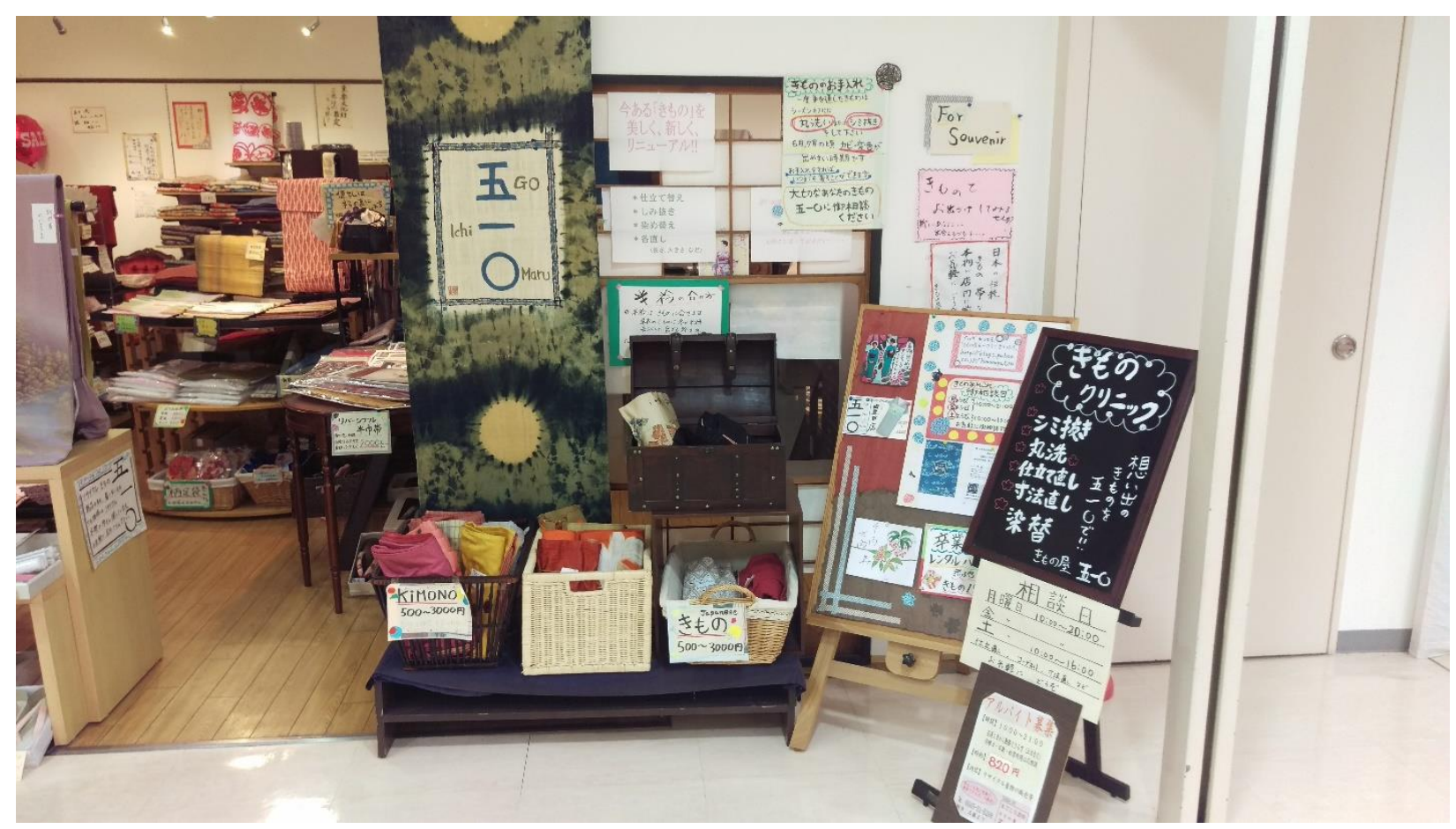

Figure 3. The outside of the shop Go-Ichi-Maru with baskets of kimono priced between 500 and 3000 yen.

The shop owners then proceed with their own selection process in deciding what they can reasonably buy and whether what they buy will be able to sell. In other words, they oversee the transition from a largely symbolic regime of value to an economic regime of value. Originally, the kimono that find their way into second-hand kimono shops have a high price tag, anywhere between 70,000 yen ( $\$ 475)$ and 600,000 yen ( $\$ 4072)$. Occasionally, kimono that are even more expensive might make their way into the second-hand kimono shop. Tansu-ya has a policy of only accepting kimono that can sell for 3000 yen or more (£20.30). A small independent shop such as Go-Ichi-Maru might make the choice to sell kimono at a lower price, such as 500 yen (£3.40). In Go-Ichi-Maru, kimono that had been made according to particular regional crafts and techniques and that were of much higher quality were usually kept out of sight in special drawers and only 
shown to interested clients. As with most types of second-hand clothing, the fewer signs of use there are, the more expensive the piece will be. Value is therefore 'mediated through bodily presences/absences' (Gregson, Brooks and Crewe 2000: 118).

The vast majority of kimono sold to second-hand shops undergo a dramatic drop in economic value. Kimono that might have been originally purchased for 500,000 yen $(£ 3,680)$ end up being sold for 1000 yen (£7.3) or less. Many people who sell their kimono are not prepared for this sheer gap in value, and are shocked when they try to sell their kimono. One of my research participants in her fifties, Kano-san, told me: 'once, just once, I took a kimono to a second-hand shop. It was a kimono I knew there was no way I would wear. It wasn't such a good one, but still... I was offered 500 yen. I couldn't believe it. I thought that at the very least they could give me 1000 yen!'

When a kimono is re-inserted into the market after having been 'singularized' and decommodified in the sense that Igor Kopytoff describes, their economic value plummets. Kopytoff argues that commodification 'homogenises' value and renders the commodity neutral in terms of symbolic value, but in the case of the kimono, that symbolic value endures beyond the point of recommodification. It is in fact this symbolic value that has a dramatic effect on economic value. When in the household, the kimono's economic value (the price it was originally purchased for) and its symbolic value (parental affection, association with a family member, etc.) are congruent. To Kano-san, it made sense that her kimono should fetch more than 1000 yen because it mattered to her and was valued by her. But to the second-hand kimono shop owner, that very same symbolic value is a hindrance, a stigma to be overcome. Customers are acutely aware that the kimono is 'used' and, in a sense, not entirely their own.

As Alexandra Palmer and Hazel Clark note, 'the tactile nature of cloth and the fact that clothes are worn on the body means that they can represent, and indeed often stand in for, human beings more forcefully than other objects' (Palmer and Clark 2005: 3). Customers of second-hand clothes are therefore engaged in a process of negotiating the 'ghost' of the person to whom the clothes initially belonged. Transition between possession and commodity, then, triggers a 'slippage' in the regimes of value and splits apart the symbolic and economic regime that had been congruent until that point. This is especially the case with second-hand kimono, as these are usually kimono that were made to order for one person. Shoppers are keenly aware of this in second-hand kimono shops. The low price tag is enticing, but the materiality of second-hand kimono confronts them with the reality of a bygone age: kimono that were made for women in the 1950s and 60s are often too small for the average Japanese woman in her $20 \mathrm{~s}$ or $30 \mathrm{~s}$ in the $21^{\text {st }}$ century, thus quite literally confronting her with the physical transformation undergone by the Japanese nation.

In spite of this, there is quite obviously a market for second-hand kimono in contemporary Japan. According to the Yano Research Institute, in 2011, second-hand kimono sales accounted for $9.5 \%$ of overall profits ${ }^{5}$. By 2017 , sales accounted for $12.3 \%$, a small but steady increase ${ }^{6}$. The growing popularity of second-hand kimono can be explained, in part, by the rising popularity of second-hand clothing worldwide (Palmer and Clark 2005: 4). With the integration of second-hand clothes into the fashion industry in the 1980s and 1990s, second-hand and vintage clothes became

\footnotetext{
${ }^{5}$ https://www.yanoresearch.com/press/pdf/1061.pdf (retrieved on 11/07/2019).

6 https://www.yanoresearch.com/en/press-release/show/press id/1812 (retrieved on 11/07/2019).
} 
desirable, even valuable (ibid). A key factor here is the relationship between materiality and time. For desirable second-hand clothing, materiality evokes a time: the colours, smells, fabrics and designs speak of a specific period, a specific designer or an ambience associated with a particular time (Baker 2012). With western clothing, nostalgia and romanticizing a particular period in history, such as the iconic 1920s and 1970s, is an important concept underpinning vintage fashion (Cassidy and Bennett 2012: 242). Vintage shoppers are highly sensitive to the materials and aesthetics associated with a particular time (DeLong, Heinemann and Reiley 2005: 24). This sensitivity to a type of aesthetics is itself a practice and technique of taste which customers develop in relation to the materiality of clothing itself. These shoppers are also motivated by the experience of shopping experience itself: looking through piles of clothes in search of the perfect item, an activity referred to by Gregson and Crewe as 'the chase' (Gregson and Crewe 2003: 9). This 'chase' clearly animated a group of about 15 young people in their 20s and 30s that I met in Nagoya. For many, their first 'kimono awakening' had been when they looked through their grandmothers' tansu and tried her kimono on. As I walked through Nagoya with them on a cool spring day in 2016, their main destinations were second-hand shops, where they would cheerfully rifle through the drawers and shelves, commenting on colours, styles and bargains, in much the same way one might hunt for bargains in ordinary shops during the sales. The attractiveness and value of these kimono are manifold: for some, it is the shape and materiality of the kimono itself that is a source of value - a point of contact with a past way of life, opposed to Western clothing. Second-hand kimono provided a safe point of entry into the world of kimono, and often younger women approached the kimono with less knowledge or understanding of what constituted 'proper' formal or informal attire. Their main lens was the vintage aesthetics and the fun of shopping.

Older women among my participants who enjoyed wearing the kimono exhibited mixed attitudes towards second-hand kimono shopping. Some took part, but chose to hide that they had purchased it second-hand. For them, the romanticisation of a time period played less of a part, and they were still utilising the knowledge about techniques and craft that they had inherited from their own mothers. They were on the lookout for good quality kimono that they could obtain at a slashed price. For these shoppers, negotiating the absent presence of a different body was not an especially confronting reality.

The value in second-hand kimono differs between generations. Manami Okazaki notes that a similar phenomenon is at play with second-hand Japanese kimono, with a growing popularity of Taisho aesthetics among women in their 20s and 30s (Okazaki 2015: 12). This growth in popularity is spurred by a number of kimono fashion magazines. One of them, Kimono Hime (literally, 'Kimono Princess') began in 2003, and showcased a 'new "kimono look" that often featured the brightly coloured, bold patterns popular in the 1920s and 1930s, styled in edgy, unconventional combinations' (Milhaupt 2014: 8). Another magazine, Nanaoh ${ }^{7}$, features a wide range of articles, suggestions on styling and care of kimono. The chief editor of Nanaoh, Yasuko Suzuki, told me that Nanaoh aimed to give 'motherly advice' to women of all generations who had questions about the kimono that their own mothers had not been able to answer.

In volume 39, issued in November 2014, Nanaoh featured an article on second-hand kimono as a way of choosing kimono in much the same way as Western clothes: quite cheaply off

${ }^{7}$ Circulation figure for January to March 2019: 28,000 
a shelf in a shop, rather than having to spend a lot of money on a made-to-order piece. The article featured suggested stylings for second-hand kimono, characterised by 'the individuality and exciting patterns that only antiques pieces have' (Nanaoh 2014: 21). This is similar to the sense of vintage Western clothes as having greater personality through their designs and materiality associated with a specific era and aesthetics. Second-hand kimono stylings and fashionalisation is also spurred by the Internet and social media (Milhaupt 2014: 9). Kimono blogs and fashion website have multiplied since the start of the $21^{\text {st }}$ century, and in 2015, Internet retail of kimono comprises $19.4 \%$ of all overall kimono sales ${ }^{8}$. To keep things in perspective, however, the people who do choose to wear second-hand kimono on some occasions remain a relatively small number of the population. That being said, the rise in consumption of second-hand kimono demonstrates a fundamental transition from one regime of value into another: kimono that began their lives oftentimes as bridal trousseau for a daughter in the second half of the $20^{\text {th }}$ century now find themselves frequently de-singularised, re-commodified and returned to the market.

\footnotetext{
${ }^{8}$ From p.25 of a 2015 report on the revival of Japanese dress by the Ministry of Economy, Trade and Industry's Manufacturing Industries Bureau available here:

https://www.meti.go.jp/committee/kenkyukai/seizou/wasou kyogi/pdf/002 03 00.pdf (retrieved 14/07/2019).
} 


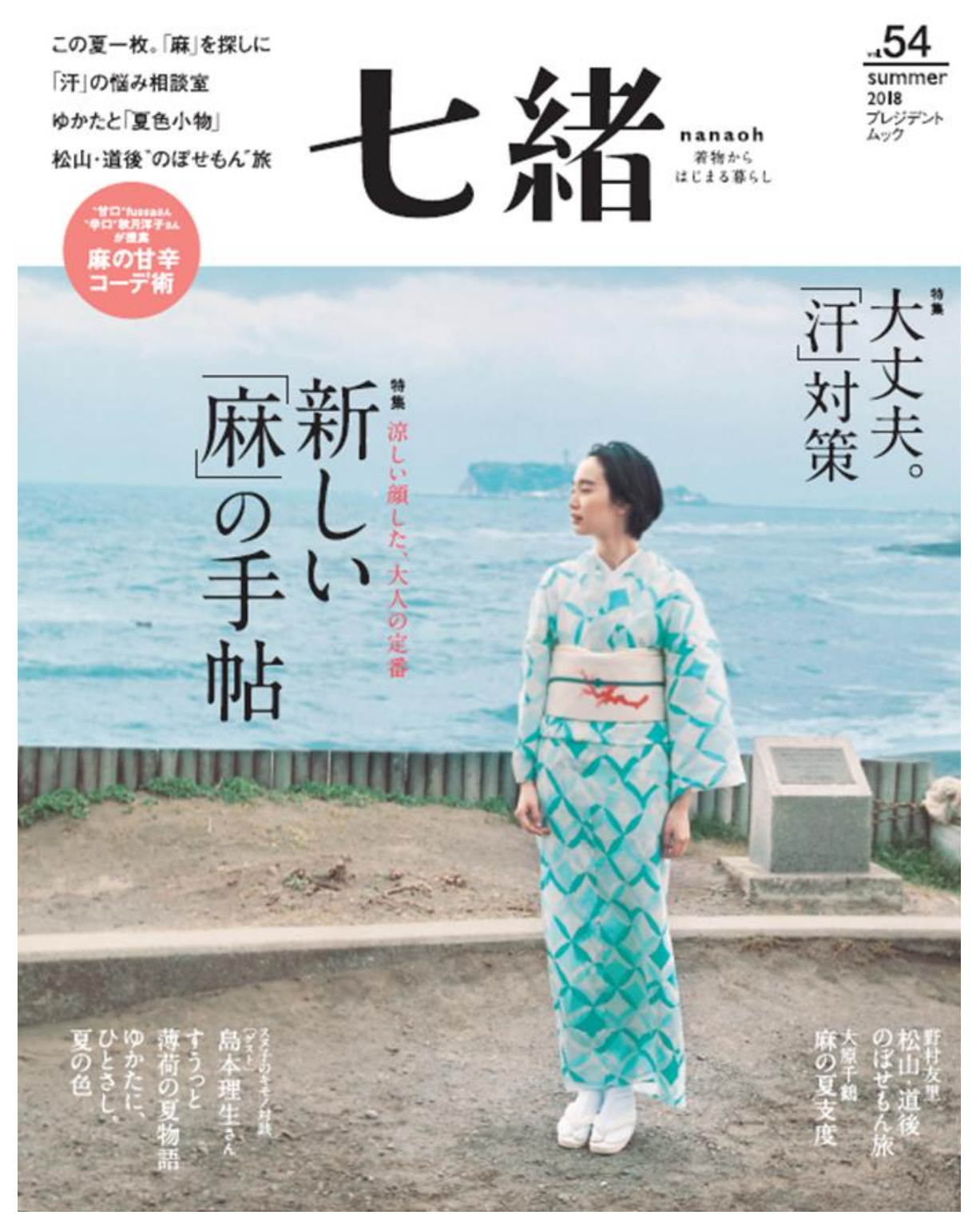

Figure 5. Cover page of the summer 2018 edition of Nanaoh, advertising summer wear. Courtesy of Nanaoh, President Inc. While this cover features a made to order kimono, Nanaoh regularly features articles on second-hand kimono shopping.

In this article, I have sought to further theorise Appadurai's under-used concept of 'regimes of value' by demonstrating how symbolic and economic regimes of value overlap, change and split apart in the context of Japan's second-hand kimono. Rather than people imposing abstract value on passive objects, I argue that the relationships people and objects, which are continually dynamic and evolving, combine with wider socio-economic and cultural processes to produce multifaceted regimes of value. By linking the process of divestment with the second-hand industry and agents such as fashion magazines, I have shown the complex process by which second-hand kimono go from commodity to possession and back to commodity once more. Upon commodification and reinsertion into the market when sold to a second-hand shop they do not completely lose their old 
symbolic value, which has to be carefully negotiated by the consumer, particularly when it comes to the bodily 'ghost' of the former owner. Finally, the second-hand kimono may move into yet another regime of value as a 'vintage' fashion item. Paying close attention to the material properties of objects, and bearing in mind the effects of time and space on this materiality, I argue that we can map how objects are entangled in the production, loss, and regeneration of value as well as the rise and fall of global processes such as fashion and consumption.

\section{Acknowledgements}

I am thankful to all my research participants for sharing their stories with me. This article is based on doctoral fieldwork supported by the Great Britain Sasakawa Foundation and the Japan Society for the Promotion of Science. The support of the Economic and Social Research Council (UK) is gratefully acknowledged, together with the Clarendon Fund, for my DPhil in Anthropology at the University of Oxford upon which this article draws. The continued support of the Economic and Social Research Council (UK) is gratefully acknowledged in the form of a postdoctoral research fellowship during which the final revisions to this article were made.

\section{References}

Appadurai, A. 1986. The Social Life of Things: Commodities in Cultural Perspective. Cambridge: Cambridge University Press

Appadurai, A. 'Commodities and the Politics of Value' in Pearce, S. M. (ed) 1994. Interpreting objects and collections. London: Routledge

Asaoka, K. 2003. Furugi (Old Clothes). Tokyo: Hōsei University Press

Author. 2018. 'From Duty to Fashion: The Changing Role of the Kimono in the Twenty-First Century' in Fashion Theory 22(3): 309-340

Baker, S. E. 2012. 'Retailing retro: Class, cultural capital and the material practices of the (re)valuation of style' in European Journal of Cultural Studies 15(5): 621-641

Bille, M., Hastrup, F. and Sørensen, T. F. 2010. An anthropology of absence: materializations of transcendence and loss. New York and London: Springer

Bourdieu, P. 'The Forms of Capital' in Richardson, J. G. 1986 Handbook of Theory and Research for the Sociology of Education. New York: Greenwood Press.

Cassidy, T. D. and Bennett, H. R. 2012. 'The Rise of Vintage Fashion and the Vintage Consumer' in Fashion Practice 4(2): 239-261

Cliffe, S. 2017. The social life of kimono: Japanese fashion past and present. London: Bloomsbury Academic

Dalby, L. 2001. Kimono: Fashioning Culture. London: Vintage 
Daniels, I. 2009. 'The "Social Death” of Unused Gifts: Surplus and Value in Contemporary Japan' in the Journal of Material Culture 14(3): 385-408

DeLong, M., Heinemann, B. and Reiley, K. 2005. 'Hooked on Vintage!' in Fashion Theory 9(1): 23-42

Editors of Nanao Magazine (Author) 2011. New Kimono: From Vintage Style to Everyday Chic. Tokyo: Kodansha International Ltd

Haggblade, S. 1990. 'The flip side of fashion: Used clothing exports to the third world' in the Journal of Development Studies 26(3): 505-521

Hansen, K. T. 2000. Salaula: the world of second-hand clothing and Zambia. Chicago; London : University of Chicago Press

Hansen, K. T. 2004a. 'Helping or hindering? Controversies around the international second-hand clothing trade' in Anthropology Today 20(4): 3-9

Hansen, K. T. 2004b. 'The World in Dress: Anthropological Perspectives on Clothing, Fashion, and Culture' in Annual Review of Anthropology 33: 369-392

Hetherington, K. 2004. 'Second-handedness: Consumption, Disposal, and Absent Presence' in Environment and Planning D: Society and Space, 22(1): 157-173

Horne, S. and Maddrell, A. 2002. Charity shops: retailing, consumption and society. London: Routledge

Goldstein-Gidoni, O. 1999. 'Kimono and the Construction of Gendered and Cultural Identities' in Ethnology 38 (4): 351-370.

Goldstein-Gidoni, O. 2001. "The Making and Marking of The "Japanese" and the "Western" in Japanese Contemporary Material Culture' in the Journal of Material Culture 6(1): 67-90

Gordon, A. 2012. Fabricating Consumers: the Sewing Machine in Modern Japan. Berkeley: University of California Press

Graeber, D. 2001. Toward an anthropological theory of value: the false coin of our own dreams. New York: Palgrave

Gregson, N., Brooks, K. and Crewe, L. 'Narratives of Consumption and the Body in the Space of the Charity/Shop' in Jackson, P., Lowe, M., Miller, D. and Mort, F. 2000. Commercial Cultures: Economies, Practices, Spaces. Oxford: Berg

Gregson, N. and Crewe, L. 2003. Second-hand cultures. Oxford: Berg

Imamura, A. 'Family Culture' in Sugimoto, Y. 2009. The Cambridge companion to modern Japanese culture. Cambridge: Cambridge University Press

Keet, P. 2011. 'Making New Vintage Jeans in Japan: Relocating Authenticity' in Textile 9(1): 4461 
Kopytoff, I. 'The Cultural Biography of Things: Commoditization as Process' in Appadurai, A. 1986. The Social Life of Things: Commodities in Cultural Perspective. Cambridge: Cambridge University Press

Milhaupt, T. S. 2014. Kimono: A Modern History. London: Reaktion Books

Manufacturing Industries Bureau (Ministry of Economy, Trade and Industry). 2016. Dai-ni kai Waso Fukō Kyōgikai kimukyoku hōukokusho (Report of Second Meeting of the Special Committee for the Revival of Japanese Dress) https://www.meti.go.jp/committee/kenkyukai/seizou/wasou_kyogi/pdf/002_03_00.pdf

Myers, F. 2001. The empire of things: regimes of value and material culture. Santa Fe, N.M.: School of American Research Press

Nakamura, K. 2006. Tansu-ya de Gozaru (This is Tansu-ya). Tokyo: Shogyokai

Niessen, S. A., Leshkowich, A. M. and Jones, C. 2003. Re-orienting fashion: the globalization of Asian dress. Oxford: Berg

Norris, L. 2004. 'Shedding Skins: The Materiality of Divestment in India' in the Journal of Material Culture 9(1): 59-71

Norris, L. 2015. 'The limits of ethicality in international markets: Imported second-hand clothing in India' in Geoforum 67: 183-193

Okazaki, M. 2015. Kimono now. Munich: Prestel

Ozawa-De Silva, C. 2002. 'Beyond the Body/Mind? Japanese Contemporary Thinkers on Alternative Sociologies of the Body' in Body \& Society 8(2): 21-38

Palmer, A. and Clark, H. 2005. Old clothes, new looks: second hand fashion. Oxford; New York: Berg

Slade, T. 2009. Japanese Fashion: A Cultural History. Oxford and New York: Berg

Tobin, J. J. 1992. Re-made in Japan: everyday life and consumer taste in a changing society. New Haven; London: Yale University Press

Weiner, A. 1992. Inalienable Possessions: The Paradox of Keeping-While-Giving. Berkeley, Los Angeles and Oxford: University of California Press

Weiss, B. 1997. 'Forgetting Your Dead: Alienable and Inalienable Objects in Northwest Tanzania' in Anthropological Quarterly 70: 163-72.

Woodward, S. 2007. Why women wear what they wear. Oxford: Berg

Yoshinaga, M. 2007. Gothic \& Lolita. London: Phaidon 